\title{
The adsorption efficiency of ceramic filter media prepared with the steel- making slag for the removal of VOCs
}

\author{
Jun Ho Sin, Tae Heui Kim and Kyung Bong Park ${ }^{\dagger}$ \\ Dept. of Materials Scienc \& Engineering, The Center for Green Materials Technology, Andong National University, Andong \\ 760-749, Korea
}

(Received March 29, 2010)

(Revised April 11, 2010)

(Accepted May 7, 2010)

\begin{abstract}
We studied the adsorption efficiency of steelmaking slag in removing volatile organic compounds (VOCs) for increasing the recycling rate of steel-making slag. Ceramic filter was prepared by mixing the steel-making slag and the diatomite which is used as adsorbents due to the advantage of the high specific surface area and regular mesopores. The adsorption efficiency for VOCs removal was about $80 \%, 96 \%$ and $85 \%$ in acetaldehyde, formaldehyde and ammonia, respectively. The adsorption efficiency over $80 \%$ for all The gases showed the practical possibility as the adsorption filter.
\end{abstract}

Key words Steel-making slag, VOSc, Ceramic filter

\section{휘발성 유기화합물 제거를 위한 제강슬래그로 제조된 세라믹 여재의 흡착효율}

신준호, 김태희, 박경봉

국립안동대학교 재료공학과, 청정소재에너지기술연구센터, 안동, 760-749

(2010년 3월 29일 접수)

(2010년 4월 11일 심사완료)

(2010년 5월 7일 게재확정)

요 약 본 연구에서는 제강슬래그의 재활용 범위를 확대하기 위하여 제강슬래그를 접촉여재로 활용한 유기화합물의 흡 착성능을 평가하였다. 또한 표면에 미세한 기공을 가지고 있어 흡착여재와 여과필터로 많은 연구가 되어온 규조토를 제강 슬래그와 혼합하여 세라믹 여재를 만들고 유기화합물 흡착 특성을 평가하였다. 유기화합물로는 아세틸알데히드, 포름알데 히드, 암모니아 기체를 사용하였으며, 각각 $80 \%, 96 \%, 85 \%$ 의 흡착 효율을 나타내었다. 사용된 모든 기체에 대해서 $80 \%$ 이상의 흡착효율을 나타내어 흡착여제로의 활용 가능성을 확인할 수 있었다.

\section{1. 서 론}

철강 산업은 그 제조공정의 특성상 다량의 원료와 에 너지를 사용할 뿐 만 아니라 다양한 부산물과 폐기물을 필연적으로 발생시키고 있다. 그 중 가장 많은 양을 차 지하는 부산물이 고로슬래그와 제강슬래그로 구분되는 철강슬래그이다[1]. 이처럼 철강 제조방법이 근본적으로 달라 지지 않는 한 현재로서는 슬래그의 발생을 피할 수 없고 철강 제조 공정과 각종 산업활동을 통하여 발생되 는 환경오염물질은 날로 증가하여 수질, 대기의 오염문 제는 갈수록 심각해져 갈 것이다. 이러한 오염물질 중

\footnotetext{
Corresponding author

Tel: +82-54-820-5427

Fax: +82-54-820-5427

E-mail:kbpark@andong.ac.kr
}

생물학적으로 분해가 어려운 난분해성 물질인 휘발성유 기화합물질(volatile organic compounds, VOCs)은 산업 공정에서 유기용제로 사용되며 이러한 유기용제들의 수 송, 저장 및 취급 시 대기로 방출된다[2]. VOCs의 유출 은 그 자체가 인체에 유해할 뿐 아니라, 대기 중에 배출 되어 질소산화물과 함께 광화학 반응을 일으킴으로써 오 존 또는 알데히드와 같은 2차 오염물질을 생성시켜 오 존층파괴 및 지구 온난화, 산성비 등으로 지구환경에 악 영향을 초래하고 있는 실정이며 $[3,4]$ 이 $\mathrm{VOCs}$ 를 제거 하기 위한 기술로 연소, 흡수, 흡착, 응축, 생화학적 여 과기술 등이 이용되고 있으나 이러한 방법들이 전적으로 만족스러운 방법은 아니다. 특히 흡착기술에서 사용되는 활성탄은 매우 고가로서 높은 운영비가 소요되는 단점으 로 인해 높은 저감효율에도 불구하고, 흡착기술 이용을 꺼리고 있다. 
따라서 본 연구의 목적은 흡착제로 이용되는 고가의 활성탄 대신 제철공장의 제강로에서 부산물로 생산되는 제강슬래그를 흡착제로 이용함으로써 운영비 절감과 동 시에 폐기물로 취급되는 제철부산물을 재활용할 수 있도 록 하는데 있다. 또한 제강 슬래그는 비교적 치밀한 구 조를 가지고 있어 단독으로 사용하기에는 적합하지 않으 므로 다공성의 규조토와 배합하여 흡착제의 조건인 다공 성을 부여 하여 $\mathrm{VOCs}$ 에 대한 흡착특성을 연구하고자 한다.

\section{2. 실험방법}

\section{1. 원료}

\subsection{1 제강슬래그}

제강 슬래그는 강을 제조하는 공정에서 새로 생성되는 상으로 취련 반응의 생성물과 $\mathrm{CaO}$ 의 반응으로 생성되며 용융 상태로 부산되는 것이 응고한 것이므로 비교적 치 밀한 조직을 갖고 Fig. 1에서 알 수 있듯이 표면에는 $10 \sim 50 \mu \mathrm{m}$ 크기의 기공이 분포하고 있음을 알 수 있다.

Table 1 의 $\mathrm{EDS}$ 에 의한 정량 및 정성분석 결과 실험에 서 사용한 제강 슬래그는 주된 구성 원소가 $\mathrm{Ca}, \mathrm{Fe}, \mathrm{Si}$, $\mathrm{Al}, \mathrm{Mg}$ 등임을 알 수 있으며 $\mathrm{Ca}$ 가 주성분으로 알칼리

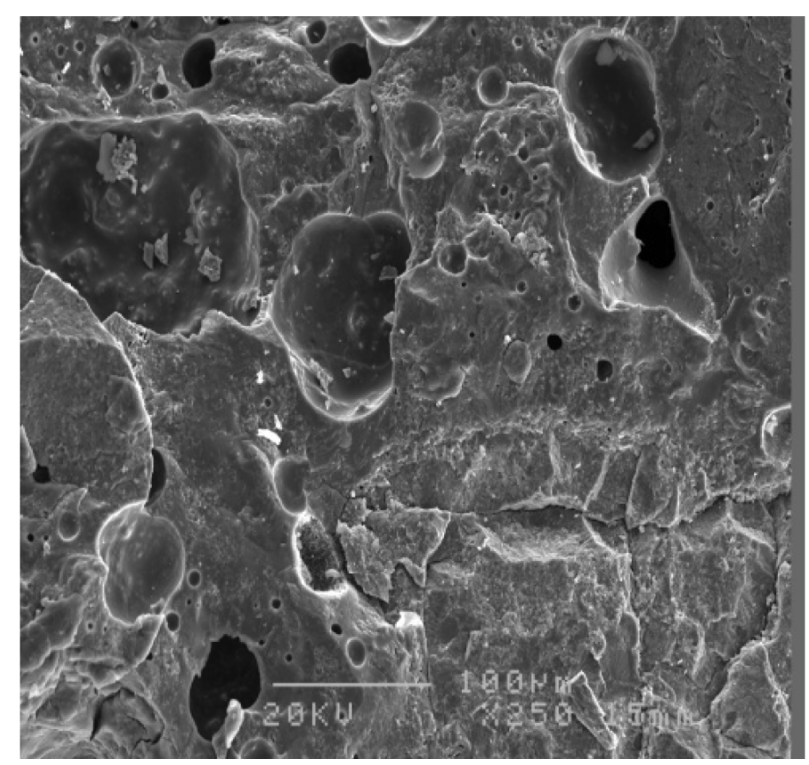

Fig. 1. SEM image of steelmaking Slag.

Table 1

EDS analysis data of steelmaking Slag

\begin{tabular}{llllllllll}
\hline Element & $\mathrm{O}$ & $\mathrm{Mg}$ & $\mathrm{Al}$ & $\mathrm{Si}$ & $\mathrm{Ca}$ & $\mathrm{Ti}$ & $\mathrm{Mn}$ & $\mathrm{Fe}$ & Total \\
\hline Content (\%) & 46.4 & 1.6 & 1.8 & 9 & 29 & 0.4 & 0.8 & 11 & 100 \\
\hline
\end{tabular}

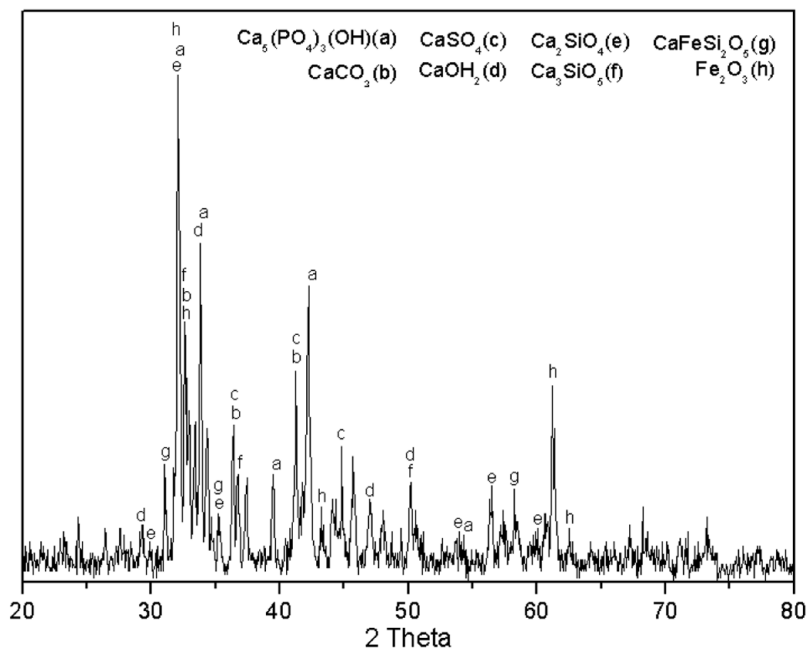

Fig. 2. XRD pattern of steelmaking Slag.

성 금속이 매우 높게 함유되어 있다.

Fig. 2 의 XRD 분석결과에서 제강슬래그의 조성은 $\mathrm{Fe}$ 의 산화물인 $\mathrm{Fe}_{2} \mathrm{O}_{3}$ 및 $\mathrm{SiO}_{2}$ 와 $\mathrm{CaO}$ 들의 고용에 따른 silicate 광물들로 구성되어 있어 흡착능이 뛰어난 광물이 다[5].

\subsection{2. 규조토}

규조토는 가루 형태로 산출되는 실리카이며 규조의 껍 질로 된 연질의 암석 또는 흙덩어리이며 규조의 유해로 서 바다나 호수 밑바닥에 침적하여 이루어지는 것이므로 함유하고 있는 불순물의 종류와 양에 따라 화학 조성이 다르며 또한 구성하는 구조의 종류에 따라 물리적 성질 을 달리한다.

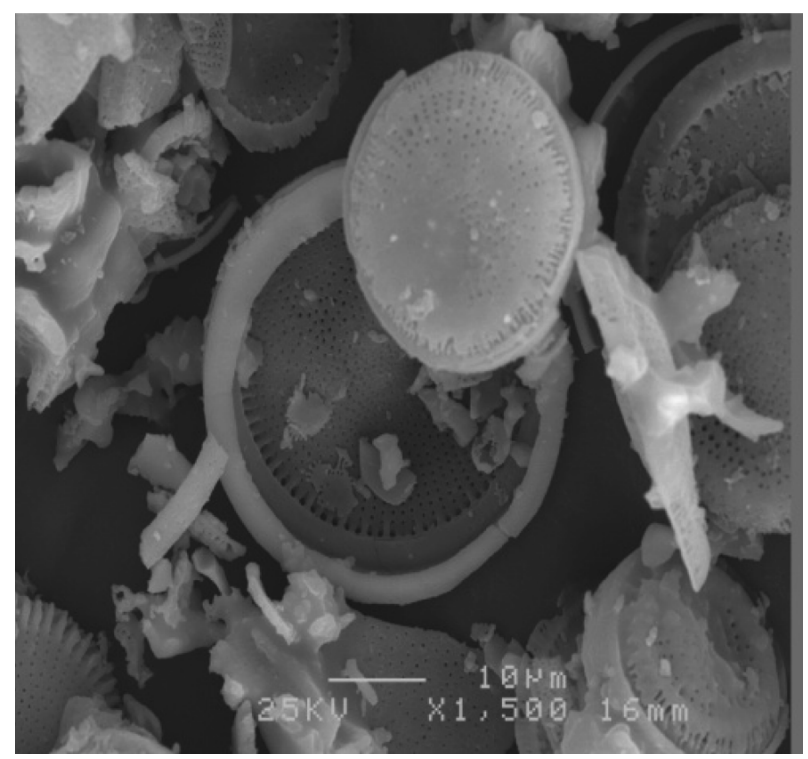

Fig. 3. SEM image of diatomite. 


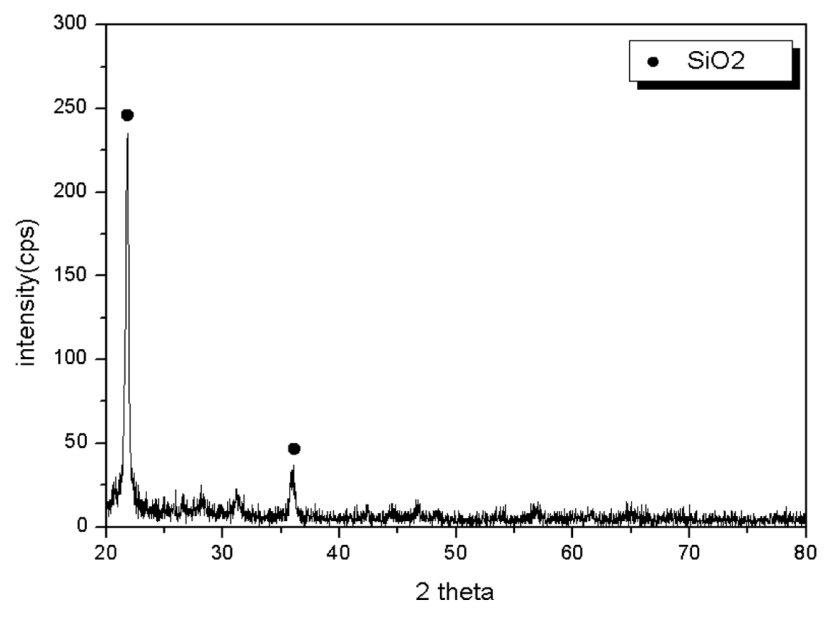

Fig. 4. XRD pattern of diatomite.

Table 2

EDS analysis data of diatomite

\begin{tabular}{llllll}
\hline Element & $\mathrm{SiO}_{2}$ & $\mathrm{Na}_{2} \mathrm{O}$ & $\mathrm{K}_{2} \mathrm{O}$ & $\mathrm{Fe}_{2} \mathrm{O}_{3}$ & $\mathrm{CuO}$ \\
\hline Content (\%) & 91.11 & 2.63 & 0.39 & 3.08 & 2.78 \\
\hline
\end{tabular}

규조토는 대부분이 구형이며 Fig. 3에서 알수 있듯이 비교적 균일한 입도 분포를 나타내고 있다. 표면에는 $5 \mathrm{~nm}$ 크기의 미세 기공이 존재하는데 이러한 특성 때문 에 흡착 여제와 여과 필터로써 많은 연구가 진행되고 있 고 세라믹 여재 제조의 첨가 원료로 우수한 특성을 가 지고 있다[6, 7].

Fig. 4와 Table 2는 XRD와 EDS를 통해 규조토의 상 과 성분을 분석한 것으로써 $\mathrm{SiO}_{2}$ 를 결정상으로 가지고 $91.11 \%$ 의 함량을 차지하고 나머지는 $\mathrm{Fe}_{2} \mathrm{O}_{3}, \mathrm{Na}_{2} \mathrm{O}, \mathrm{CuO}$, $\mathrm{K}_{2} \mathrm{O}$ 등이 있다.

\section{2. 세라믹 여제의 제조}

제강슬래그만을 이용하여 흡착여재를 만들 경우 여재 의 형상이 어렵고 소결성이 좋지 않으므로 규조토와 함 께 배합하여 세라믹 여재를 제작하였다. 규조토를 첨가 하여 세라믹 여재의 제조에 사용할 제강슬래그의 입도가 고르지 못하고 크기 때문에 jaw crusher를 이용하여 조 분쇄한 후 다시 attrition mill에서 20시간 분쇄한 후 사 용하였다. 규조토는 입자가 고르고 부드러우므로 조분쇄 공정 없이 attrition mill에서 20시간 분쇄한 후 사용하였 다. 제강슬래그와 규조토의 배합비는 $1: 1$ 로 하였고 성 형의 용이성과 기공형성을 위하여 첨가한 $\mathrm{PVA}$ 의 양은 원료 분말에 대해 $30 \%$ 로 하여 배합하였다.

배합한 분말에 일정량의 증류수를 첨가하여 습식혼합 후 실리더 형의 steel mold를 이용해 지름 $10 \mathrm{~mm}$, 높이 $20 \mathrm{~mm}$ 의 원기둥 모양으로 압출하여 성형하였다. 성형한

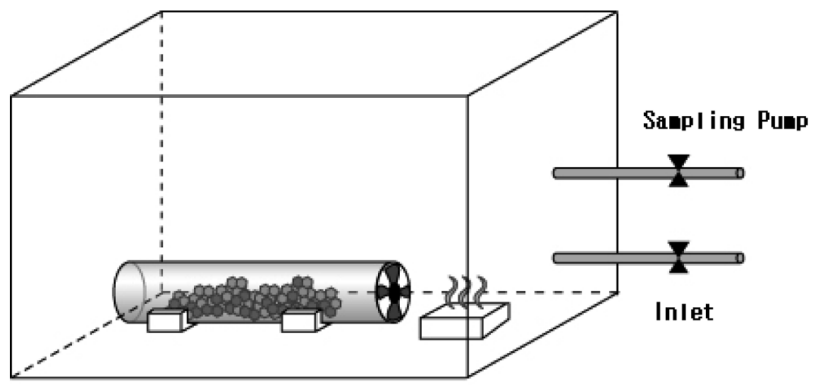

Fig. 5. Schematic diagram of apparatus for measuring the adsorption efficiency.

시편은 $120^{\circ} \mathrm{C}$ 온도의 건조기에서 20 시간 동안 건조시켜 수분을 증발 시켰다. 이후 소성 단계에서 결합제를 제거 하기 위해서 $500^{\circ} \mathrm{C}$ 에서 1 시간 유지 후 $1100^{\circ} \mathrm{C}, 1$ 시간 소성하였다.

\section{3. 흡착 실험}

제강슬래그의 VOCs 제거 실험을 위해서 Fig. 5와 같은 반응용기를 제작하였다. 지름: $105 \mathrm{~mm}$, 높이: $310 \mathrm{~mm}$ 의 원통 아크릴에 제강슬래그를 $80 \%$ 충진하고 $\mathrm{VOCs}$ 의 원활한 순환을 위해 양 옆에 팬을 설치하였다. 제작된 칼럼은 가로: $50 \mathrm{~cm}$, 세로: $50 \mathrm{~cm}$, 높이: $50 \mathrm{~cm}$ 인 아크 릴로 제작된 통에 장착하였다. 본 실험에 사용한 $\mathrm{VOCs}$ 는 아세트알데하이드, 포름알데하이드, 암모니아로써 특 급시약을 구입하여 전 처리 없이 사용하였으며 acrylic chamber 내에서 일정 시간 동안 기화시킨 후 팬을 틀어 대류 시켰다. 모든 액상이 기화되는 시간을 0 으로 하여 5 분 간격으로 30 분간 측정하였다. 측정 장치는 GV-100 Gas Sampling Pump를 이용하여 각 VOC에 맞는 gastec tube를 사용하여 측정하였고 측정하기 전 팬을 끄고 대 기를 1 분간 안정화 시킨 후 측정하였다.

\section{3. 결과 및 고찰}

\section{1. 세라믹 여제 분석}

제강슬래그는 비교적 치밀한 조직을 갖고 있다. 또한 제강 슬래그만을 조분쇄하여 세라믹 여재를 만들 경우 여재의 형상이 어렵고 소결성이 좋지 못하므로 규조토와 의 배합으로 여재를 형성하였다.

Fig. 6은 제조된 세라믹 여재의 표면을 SEM을 통해 관찰한 사진으로 제강 슬래그에 비해 개기공의 빈도수가 증가하였고 $10 \sim 20 \mu \mathrm{m}$ 의 미세 기공들이 많아진 것을 확 인할 수 있는데 기공의 크기와 기공의 분포에 있어서 바 람직하다고 할 수 있다. 


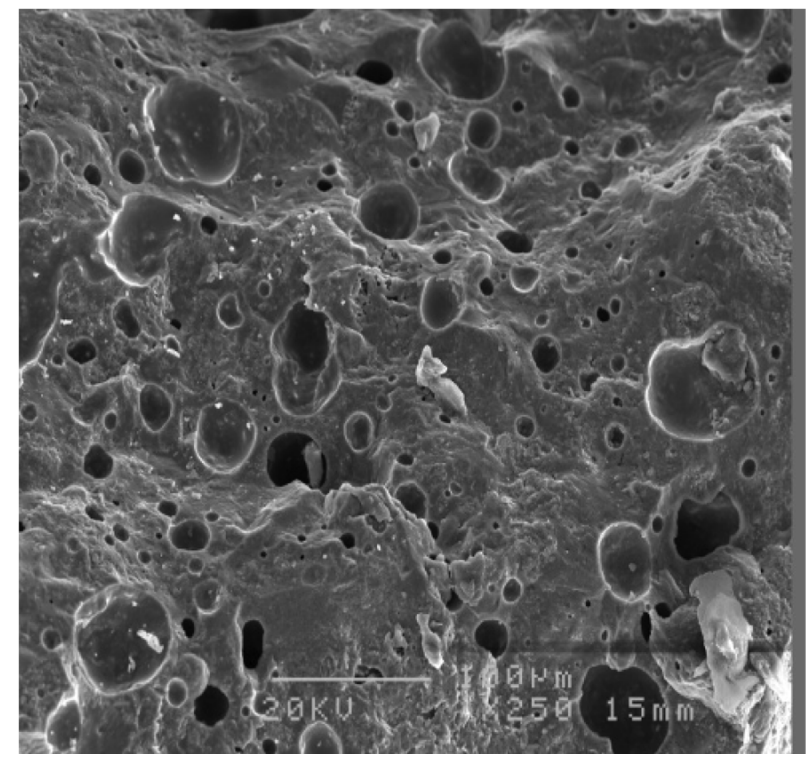

Fig. 6. SEM image of surface of filter media.

\section{2. 흡착 실험}

Fig. 7은 제강슬래그(S)와 세라믹 여재(SD)의 VOCs 제거 특성을 나타낸 것이다. 그림에서 알 수 있듯이 일 정농도의 아세트알데하이드 $(500 \mathrm{ppm})$, 포름알데하이드 $(510 \mathrm{ppm})$, 암모니아 $(490 \mathrm{ppm})$ 가 포함된 밀폐된 공간에 두 종류의 흡착여재를 각각 넣고 30 분 동안 흡착 실험 결과 제강슬래그를 단독으로 사용하였을 때는 아세트알 데히드, 포름알데히드, 암모니아에 대해서 각각 $19 \%$, $89 \%, 68 \%$ 의 흡착 특성을 나타내었는데, 이는 제강슬 래그 만으로 포름알데히드와 암모니아에 대해서는 $60 \%$ 이상의 유기물 흡착 효율을 나타내지만 아세트알데히드 에 대해서는 치밀한 조직에 따른 영향으로 매우 낮은 흡 착효율을 나타내었다.

규조토와 배합하여 제조한 세라믹 여재(SD)의 경우에 는 아세트알데히드, 포름알데히드, 암모니아에 대해서 각 각 $80 \%, 96 \%, 85 \%$ 를 나타내었는데 이는 제강슬래그 의 기본 흡착특성과 규조토와의 배합으로 생긴 다량의 기공으로 인한 기공 분포의 증가로 기체를 흡착할 수 있 는 표면적이 크게 증가한 것에 기인한 것으로 생각되며, 이 결과로부터 규조토와 제강슬래그를 배합하여 제조된 세라믹 여재가 본 실험에서 사용된 세 가지 유기화합물 에 대하여 흡착여재로서 사용이 가능하리라 생각된다.

\section{4. 결 론}

1) 제철공정에서 부산물로 생산되는 제강슬래그는 $\mathrm{Ca}$, $\mathrm{Fe}, \mathrm{Si}, \mathrm{Al}, \mathrm{Mg}$ 등 알칼리 금속을 다량으로 함유하고 $\mathrm{Fe}$

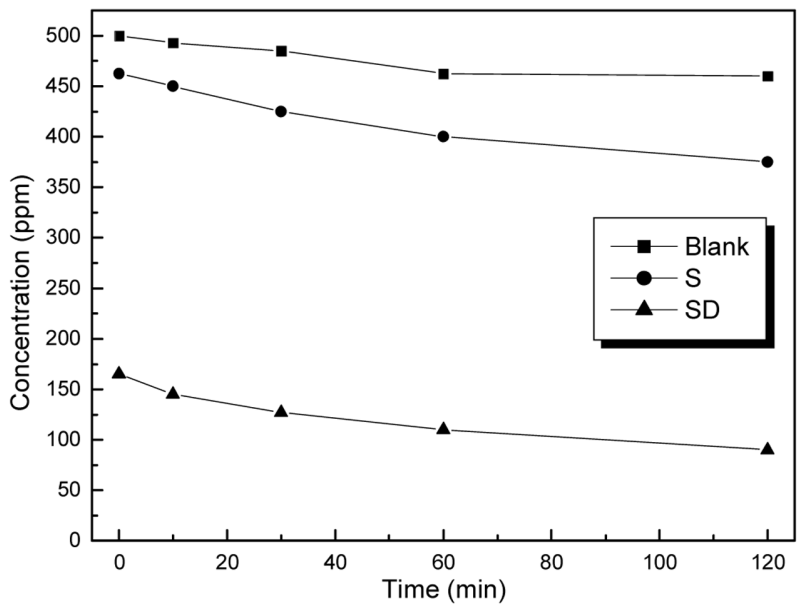

(a) Acetaldehyde

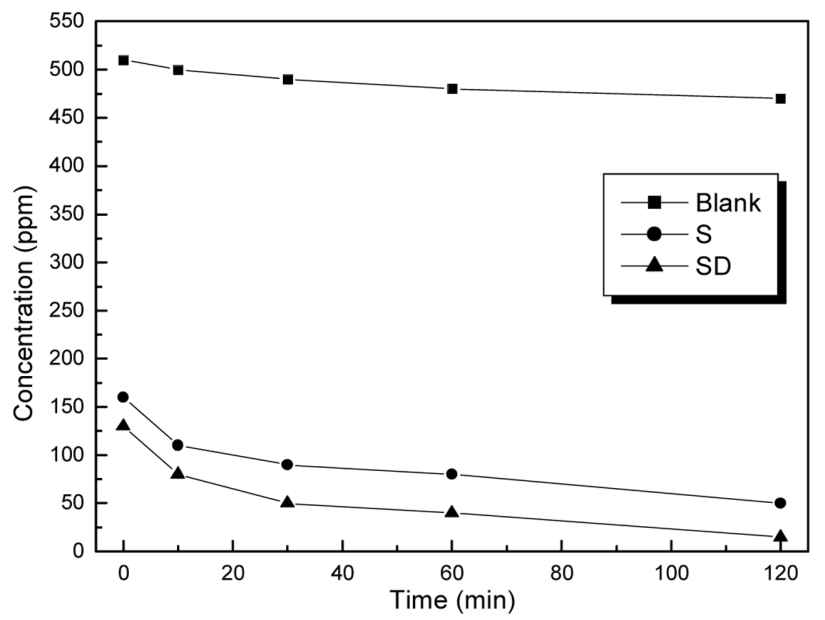

(b) Formaldehyde

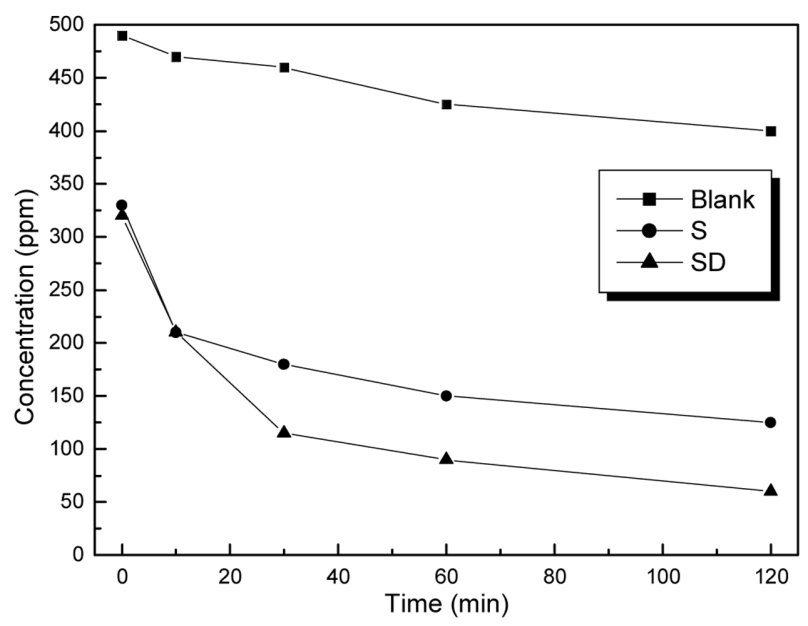

(c) Ammonia

Fig. 7. Concentration change of VOCs.

산화물인 hematite, $\mathrm{SiO}_{2}$ 와 $\mathrm{CaO}$ 의 고용에 따른 Silicate 광물들로 구성되어 있음을 알 수 있었다.

2) 비교적 치밀한 구조를 가지고 있는 제강슬래그는 규조토와의 가공으로 $10 \sim 20 \S$ 의 기공 크기를 가지는 세 라믹 여재를 만들 수 있었다. 
3) 공기순환방식으로 시간에 따른 VOCs 농도를 측정 한 결과 아세틸알데히드, 포름알데히드, 암모니아에 대해 서 제강슬래그 만으로는 $19 \%, 89 \%, 68 \%$ 의 흡착 효 율을 나타내고, 규조토와 제강슬래그의 배합으로 제조된 세라믹여재(SD)로는 $80 \%, 96 \%, 85 \%$ 의 흡착 효율을 얻었다.

\section{감사의 말씀}

이 논문은 2007학년도 안동대학교 특성화추진지원사 업에 의하여 연구되었음.

\section{참 고 문 헌}

[1] J.M. Kim, E.G Kwak and K.S. Bae, "The properties of underwater hardening epoxy mortar used the rapidly cooled steel slag", J. KCI Structural 19(5) (2007) 549.

[2] K.H. Kim, I.S. Kil and D.H. Kim, "Adsorption characteristics of VOCs in activated carbon beds", J. KOSAE, 24(4) (2008) 455.

[3] B.B. weinberger and R.B. Garber, "Titanium dioxide photocatalysts produced by reactive magnetron sputtering", Appl. Phys. Lett. 66(18) (1995) 2409.

[4] J. Augustynski, "The role of the surface intermediates in the photoelectrochemical behavior of anatase and rutile $\mathrm{TiO}_{2}$ ”, J. Electrochem. Ata. 38(1) (1993) 43.

[5] J.H. Hyun, M.G. Kim, I.Y. Nam and J.S. Baek, "Removal of heavy from wastewater using steelmaking slag and sludge", J. of Korean Inst. of Resources Recycling 8(1) (1999) 11.

[ 6 ] S.S. Lee, J.S. Kim, C.Y. Yunn and J.H. Yi, “Adsorption characteristics of the sericite and diatomite for ammonia gas", Clean Technology 12(3) (2006) 175.

[7] D.Y. Shin, J.Y. Kim and S.N. Ji, "A study on the drinking water treatment by precoat filtration and activated carbon adsorption process", Kor. J. Env. Hlth 30(5) (2004) 402. 